\title{
Development and Characterization of a Human Hepatocyte Low Intrinsic Clearance Assay for Use in Drug Discovery ${ }^{\text {[ }}$
}

\author{
Paul Lancett, ${ }^{1}$ Beth Williamson, ${ }^{1}$ Patrick Barton, and Robert J. Riley \\ Drug Metabolism and Pharmacokinetics, Evotec, Abingdon, Oxford, United Kingdom
}

Received March 23, 2018; accepted May 16, 2018

\begin{abstract}
Progression of new chemical entities is a multiparametric process involving a balance of potency; absorption, distribution, metabolism, and excretion; and safety properties. To accurately predict human pharmacokinetics and estimate human efficacious dose, the use of in vitro measures of clearance is often essential. Low metabolic clearance is often targeted to facilitate in vivo exposure and achieve appropriate half-life. Suspension primary human hepatocytes (PHHs) have been successfully used in predictions of clearance. However, incubation times are limited, hindering the limit of quantification. The aims herein were to evaluate the ability of a novel PHH media supplement, HepExtend, in order to maintain cell function, increase culture times, and define the clearance of stable compounds. Cell activity was analyzed with a range of cytochrome P450 (P450) and UDP-glucuronosyltransferase (UGT) substrates, and the mRNA expression of drug disposition and toxicity marker genes was
\end{abstract}

\section{Introduction}

A critical practice for the robust design of discovery compounds is the implementation of early absorption, distribution, metabolism, and excretion assessment. The design process is a multiparametric process involving a balance of in vitro and in vivo potency; absorption, distribution, metabolism, and excretion; and safety properties. Early prediction of human pharmacokinetics (PK) can be used to rank compounds to ensure efficient drug design and project progression. To accurately predict human $\mathrm{PK}$ and estimate human efficacious dose, measurement of intrinsic clearance $\left(\mathrm{CL}_{\mathrm{int}}\right)$ in vitro is a common method for the estimation of human hepatic clearance (CL) (Grime et al., 2013).

Low metabolic CL is often targeted to facilitate in vivo exposure and achieve appropriate half-life (Riley et al., 2005; Grime and Riley, 2006; Sohlenius-Sternbeck et al., 2012; Di and Obach, 2015). For compounds with moderate volume of distribution $(\sim 2 \mathrm{~L} / \mathrm{kg})$ and low CL $(\leq 3.5 \mathrm{ml} / \mathrm{min} / \mathrm{kg}$ ), the ability of drug metabolism and PK scientists to accurately determine in vitro $\mathrm{CL}_{\mathrm{int}}$ is necessary since small changes in CL may have significant impact on the predicted half-life and anticipated human dose (Grime et al., 2013; Bonn et al., 2016).

Suspension primary human hepatocytes (PHHs) containing phase I and II metabolizing enzymes have been successfully used in predictions

\footnotetext{
${ }^{1}$ P.L. and B.W. contributed equally to this work.

https://doi.org/10.1124/dmd.118.081596.

SThis article has supplemental material available at dmd.aspetjournals.org.
}

determined. HepExtend and Geltrex were essential to maintain cell activity and viability for 5 days ( $N=3$ donors). In comparison with CM4000 \pm Geltrex, HepExtend + Geltrex displayed a higher level of gene expression on day 1, particularly for the P450s, nuclear receptors, and UGTs. The novel medium, HepExtend + Geltrex, was robust and reproducible in generating statistically significant intrinsic clearance values at $0.1 \mu \mathrm{l} / \mathrm{min} / 10^{6}$ cells over a 30-hour period $(P<0.05)$, which was lower than previously demonstrated. Following regression correction, human hepatic in vivo clearance was predicted within 3 -fold for $83 \%$ of compounds tested for three human donors, with an average fold error of 2.2. The novel PHH medium, HepExtend, with matrix overlay offers significant improvement in determining compounds with low intrinsic clearance when compared with alternative approaches.

ABBREVIATIONS: AFE, average fold error; $\mathrm{CL}$, clearance; $\mathrm{CL}_{\text {int }}$, intrinsic clearance; $\mathrm{C}(\mathrm{t})$, comparative threshold; $\mathrm{DMSO}$, dimethylsulfoxide; $\mathrm{LLOQ}$, lower limit of quantification; P450, cytochrome P450; PHH, primary human hepatocyte; PK, pharmacokinetics; RT, reverse transcription; UGT, UDPglucuronosyltransferase; WEM, Williams' E medium.

of compound CL (Riley et al., 2005; Grime and Riley, 2006; SohleniusSternbeck et al., 2012). However, incubation times are limited to 2-4 hours due to declining levels of metabolizing activity and an increase in cell mortality, hindering the limit of quantification (Smith et al., 2012). This major limitation has driven the advancement of alternative in vitro approaches.

A myriad of alternatives have been evaluated and reviewed by various laboratories (Lau et al., 2002; Novik et al., 2010; Smith et al., 2012; Chan et al., 2013; Di and Obach, 2015; Hutzler et al., 2015). Many share a common goal: to implement more phenotypically relevant models with prolonged metabolizing activity to aid in vivo hepatic metabolic CL predictions. The relay method and monolayer/sandwich-cultures of plated PHHs represent two techniques that have been widely appraised for their ability to predict in vivo CL of stable compounds (Riley et al., 2005; Grime and Riley, 2006; Di et al., 2012; Peng et al., 2016). While the continuous replenishment of freshly prepared PHHs overcomes the issue of limited incubation times in suspension assays (Di et al., 2012, 2013), the requirement for substantial volumes of PHHs makes the relay method a labor-intensive approach requiring complex data processing (Di et al., 2012; Hutzler et al., 2015; Peng et al., 2016).

When seeded on collagen-coated plates, $\mathrm{PHH}$ viability can be retained for 5 days, and longer with the addition of an overlay, e.g., Geltrex (Keemink et al., 2015; Levy et al., 2015). Plating PHHs with an overlay facilitates polarization of the monolayer, enabling formation of bile canaliculi and localization of transporters, thus improving the physiologically relevant phenotype (De Bruyn et al., 2013). However, conflicting literature regarding 
CYP3A4 and CYP1A2 activities (Smith et al., 2012) suggests further optimization of this technique is required to ensure optimum metabolic function.

Over the last decade, advances have seen the application of PHHs cocultured with nonparenchymal cells in two- and three-dimensional culture (Khetani and Bhatia, 2008; Chan et al., 2013; Hutzler et al., 2015; Bonn et al., 2016). Technologies such as HepatoPac and H $\mu$ REL have been shown to maintain liver-specific drug-metabolizing enzyme gene expression for up to 6 weeks (Khetani and Bhatia, 2008) and have been successfully used for human CL predictions, including stable compounds (Chan et al., 2013; Bonn et al., 2016). However, when contextualized in a discovery setting, coculture methods do not yet offer the throughput often sought (Hutzler et al., 2015). The same rationale can also be applied to other emerging technologies, including further three-dimensional models (Chen et al., 2010; Tostões et al., 2011; Godoy et al., 2013) and dynamic flow models (e.g., LiverChip), which display improved hepatic physiology and phenotype (Vivares et al., 2015) but are limited by throughput and translation to in vivo settings (Hutzler et al., 2015).

Cells derived from induced pluripotent stem cells, e.g., iCell are an emerging technology that are expected to offer a high-throughput and flexible platform. Initial analysis suggests these cells exhibit hepatic morphology and functions (Rashid et al., 2010; Si-Tayeb et al., 2010; Chen et al., 2012). However, metabolic activities have been reported to be at least 10-fold lower when compared with PHHs. Further investigation is required to understand their optimal application in a discovery setting (Kratochwil et al., 2017). Cytochrome P450 (P450) activity levels comparable to PHHs have been purported for the pluripotent cell line HepaRG (Turpeinen et al., 2009).

The aims herein were to evaluate the application of a novel plated PHH media supplement, HepExtend, regarding its ability to maintain cell function, increase culture times, and define a lower limit of quantification (LLOQ) in order to improve human hepatic metabolic CL predictions. HepExtend was compared with the widely used $\mathrm{PHH}$ maintenance medium (CM4000) and the necessity of an overlay for optimal performance was also evaluated.

\section{Materials and Methods}

Materials. Primary human hepatocytes (lots Hu1753, Hu8249, and Hu1824) were kindly supplied by Thermo Fisher Scientific (Paisley, Scotland). Hepatocyte thawing media, Primary Hepatocyte Thawing and Plating Supplements (CM3000), Primary Hepatocyte Maintenance Supplements (CM4000), collagen-1 coated 24-well plates, Geltrex LDEV-Free Reduced Growth Factor Basement Membrane Matrix $(0.35 \mathrm{mg} / \mathrm{ml})$ (a gel matrix additive), HepExtend Supplement (50X), reverse transcription (RT) reagents, universal master mix, Williams' E medium (WEM), TRIzol Plus RNA Purification Kit, and Taqman gene expression assays were purchased from Thermo Fisher Scientific. All other materials were purchased from Sigma-Aldrich (Dorset, United Kingdom).

Cryopreserved Human Hepatocyte Cell Culture. Plateable cryopreserved PHHs (Table 1) were thawed in hepatocyte thawing medium and plated in a 24 -well collagen- 1 coated plate at a density of $3.5 \times 10^{5}$ viable cells in $350 \mu \mathrm{l}$ of
WEM/plating supplement. Trypan blue exclusion was used to determine cell viability with a cutoff of $90 \%$ viability. The cells were incubated at $37^{\circ} \mathrm{C}$ in a $95 \%$ humidified incubator with $5 \% \quad \mathrm{CO}_{2}$. Plating medium was replaced with $\mathrm{WEM}$ /maintenance medium following 4- to 6-hour incubation and then maintained overnight before 30-hour treatment with test compound. Each donor was incubated with the following four WEM/maintenance medium:

1. CM4000;

2. CM4000 + Geltrex (hereinafter described as CM4000 + Geltrex);

3. CM4000 + HepExtend (hereinafter described as HepExtend); and

4. CM4000 + HepExtend + Geltrex (hereinafter described as HepExtend + Geltrex)

Plates were shaken at $50 \mathrm{rpm}$ and samples were collected at $0,1,2,4,8,22,26$, and 30 hours. Then, $40 \mu \mathrm{l}$ samples were quenched in $160 \mu \mathrm{l}$ of acetonitrile containing $0.1 \%$ formic acid and $200 \mathrm{nM}$ of labetalol as the internal standard. Samples were shaken for 5 minutes at $1200 \mathrm{rpm}$, cooled at $-20^{\circ} \mathrm{C}$ for 5 minutes, and then centrifuged at $4^{\circ} \mathrm{C}$ for 10 minutes at $4600 \mathrm{rpm}$. The supernatant fraction was diluted in an equal volume of water and quantification of parent analyzed using liquid chromatography-tandem mass spectrometry.

Following the 30-hour compound incubation the cells were carefully washed with WEM/maintenance medium and incubated with fresh WEM/maintenance medium at $37^{\circ} \mathrm{C}$ in a $95 \%$ humidified incubator with $5 \% \mathrm{CO}_{2}$ for 48 hours before compound treatment was initiated on day 5 following the procedure described previously. For gene expression analysis, mRNA was extracted on day 1 or 5 .

Compound Treatment. For comparison of the four media in the assay a set of reference compounds were selected based on their human $\mathrm{CL}$ and in vitro $\mathrm{CL}_{\text {int }}$ (Table 2). Reference compound $\mathrm{CL}_{\text {int }}$ ranged from 0.1 to $20 \mu \mathrm{l} / \mathrm{min} / 10^{6}$ cells. For all incubations, compounds were dissolved in $100 \%$ dimethylsulfoxide (DMSO) to $2 \mathrm{mM}$, and compounds were then diluted to $0.1 \mathrm{mM}$ with acetonitrile:DMSO (91.5:8.5\%, respectively). A final compound dilution with maintenance medium was completed to achieve a final DMSO concentration of $0.1 \%$ and compound concentration of $1 \mu \mathrm{M}$. A vehicle control of medium with $0.1 \%$ DMSO was included in all studies.

Determination of Intrinsic Clearance. Loss of parent compound over the 30-hour incubation was used to calculate the in vitro $\mathrm{CL}_{\mathrm{int}}$ on days 1 and 5 of treatment. Only compounds with statistically significant $\mathrm{CL}_{\text {int }}$ values $(P<0.05)$ as defined by the T-statistic were included in the analysis. In vitro $\mathrm{CL}_{\text {int }}$ was transformed to a predicted human in vivo $\mathrm{CL}_{\text {int }}$ by applying physiologic scaling parameters and an incubational binding value (Kilford et al., 2008). A regression correction method was used to predict in vivo $\mathrm{CL}_{\text {int }}$ as described previously (Sohlenius-Sternbeck et al., 2012). Observed human in vivo $\mathrm{CL}_{\text {int }}$ was calculated using the well-stirred model.

The $\mathrm{CL}_{\text {int }}$ values were scaled to the whole liver by applying physiologic scaling factors and incubational binding (i.e., the fraction unbound in the incubation). The fraction unbound in the incubation value was predicted by applying a nonlinear equation as detailed by Kilford et al. (2008). While the equation displays relatively accurate and nonbiased results for a range of compounds with $\log \mathrm{P}<3$, the algorithm is based on suspension hepatocytes. Limited data exist to quantify the incubational binding in a plated hepatocyte assay and further work is required to understand this parameter. Nonetheless, similar to previous studies (Bonn et al., 2016), the nonlinear equation was applied to the data herein (Figs. 1 and 2).

Application of Regression Correction. The blood-to-plasma ratio and fraction unbound was determined previously (Obach et al., 2008; SohleniusSternbeck et al., 2012); however, when no measured blood-to-plasma ratio value was available, a default value of 0.55 (1-hematocrit) was assumed for acidic compounds and a value of 1 was assumed for other ion classes. To establish the

TABLE 1

Human donor demographics of the hepatocytes used in the study

\begin{tabular}{cllcccccc}
\hline Donor & \multicolumn{1}{c}{ Ethnicity } & Gender & Age & BMI & Tobacco History & Alcohol History & Drug History & Medication \\
\hline Hu1753 & Caucasian & Female & 43 & 22 & Yes & Yes & None reported & Scopolamine ${ }^{a}$ \\
Hu1824 & Caucasian & Female & 66 & 28 & Yes & No & None reported & None reported \\
Hu8249 & African American & Male & 29 & 22 & Yes & Yes & Yes & None reported \\
\hline
\end{tabular}

BMI, body mass index.

${ }^{a}$ Medication given via patch; dosage: $1.5 \mathrm{mg}$ transdermal every 72 hours as needed 
TABLE 2

Physicochemical properties and human clearance values for the compounds included in the analysis

Overview of the validation compounds used in the analysis; $\log D$ is quoted for acids and neutrals and log $P$ is quoted for bases (see Sohlenius-Sternbeck et al., 2012; Chan et al., 2013; Hutzler et al., 2015).

\begin{tabular}{|c|c|c|c|c|c|}
\hline Compound & Metabolizing Enzyme & Chemical Class & $\log \mathrm{D} / \mathrm{P}$ & Human $\mathrm{fu}_{\mathrm{p}}$ & Human In Vivo CL \\
\hline & & & & & $\mathrm{ml} / \mathrm{min} / \mathrm{kg}$ \\
\hline Bupropion & $\begin{array}{l}\text { CYP2B6, CYP1A2, CYP2A6, } \\
\text { CYP3A4, CYP2E1 }\end{array}$ & Base & 3.27 & 0.15 & 10.45 \\
\hline Carvedilol & CYP2D6, CYP2C9 & Base & 3.42 & 0.02 & 7.80 \\
\hline Diazepam & CYP2C19, CYP3A4 & Neutral & 2.8 & 0.023 & 0.38 \\
\hline Diclofenac & CYP2C9, UGT2B7 & Acid & 1.12 & 0.005 & 4.20 \\
\hline Disopyramide & CYP3A4 & Base & 2.58 & 0.16 & 0.90 \\
\hline Ethinyl estradiol & UGT1A1, CYP3A4 & Acid & 4.11 & 0.01 & 5.0 \\
\hline Imipramine & CYP1A2, CYP2C19, CYP2D6 & Base & 4.28 & 0.075 & 9.50 \\
\hline Metoprolol & CYP2D6, CYP3A4 & Base & 1.76 & 0.88 & 13.30 \\
\hline Midazolam & CYP3A4 & Neutral & 3.4 & 0.017 & 4.60 \\
\hline Sildenafil & CYP3A4, CYP2C9, CYP2C19 & Base & 2.8 & 0.04 & 6.00 \\
\hline Tolbutamide & CYP2C9 & Acid & 0.47 & 0.05 & 0.17 \\
\hline Warfarin & CYP2C9, CYP3A4 & Neutral & 0.2 & 0.015 & 0.05 \\
\hline
\end{tabular}

$\mathrm{fu}_{\mathrm{p}}$, fraction unbound in plasma; $\log \mathrm{D}$, distribution coefficient; $\log \mathrm{P}$, partition coefficient.

regression line, $\log$ (in vivo $\mathrm{CL}_{\text {int }}$ ) was compared with $\log$ (in vitro scaled, unbound $\mathrm{CL}_{\text {int }}$ ). The regression correction was then applied to the scaled in vitro $\mathrm{CL}_{\mathrm{int}}$. From this correction the restricted well-stirred model could be applied to achieve a prediction of in vivo CL.

mRNA Extraction and Reverse Transcription. mRNA was extracted from the PHH cell monolayers using the TRIzol Plus RNA Purification Kit according to manufacturer's instructions. Reverse transcription of mRNA to complementary DNA was completed using Taqman RT assay. RT mixtures were prepared according to the manufacturer's instructions; $25 \mu$ l reactions consisted of $10 \mathrm{X}$ Taqman RT buffer, $\mathrm{MgCl}_{2}(5.49 \mathrm{mM})$, reverse transcriptase (1 $\left.\mu \mathrm{M}\right)$, RNA (2 $\left.\mu \mathrm{g}\right)$, dNTP $(50 \mu \mathrm{M})$, oligo-d(T) $(2.5 \mu \mathrm{M})$, and RNase inhibitor $(1 \mu \mathrm{M})$. An Agilent Mx3005P thermocycler (Santa Clara, CA) was used to run a thermal cycle of 10 minutes at $25^{\circ} \mathrm{C}, 30$ minutes at $37^{\circ} \mathrm{C}, 5$ minutes at $95^{\circ} \mathrm{C}$, and a hold phase at $4^{\circ} \mathrm{C}$

Quantitative Real-Time Polymerase Chain Reaction Gene Expression Analysis. An Agilent Mx3005P thermocycler was used to determine the gene expression of 45 selected drug disposition genes plus three housekeeping genes (glyceraldehyde-3-phosphate dehydrogenase, glucuronidase beta, and ribosomal RNA 18s) (Supplemental Table 1). Real-time polymerase chain reaction Taqman solutions were prepared as described by the manufacturer. Briefly, each reaction contained a $12.5 \mu \mathrm{l}$ volume: $2 \mathrm{X}$ Taqman master mix (6.3 $\mu \mathrm{l}), 20 \mathrm{X}$ Taqman gene expression assay $(0.6 \mu \mathrm{l})$, RNase free water (3.6 $\mu \mathrm{l})$, and $2 \mu \mathrm{l}$ of complementary DNA. Polymerase chain reaction conditions were 15 minutes at $95^{\circ} \mathrm{C}$ (to activate polymerase, denature complementary DNA, and initiate polymerase chain reaction) followed by 40 cycles of 15 seconds at $94^{\circ} \mathrm{C}$ (denaturation) and 60 seconds at $60^{\circ} \mathrm{C}$ (annealing/extension of the product). Fluorescence was measured at the end of each cycle.

No template controls were completed in duplicate to ensure no contamination, specific amplification, and maximum amplification. A geometric mean was used to average the three housekeeping controls (glyceraldehyde-3-phosphate dehydrogenase, glucuronidase beta, and ribosomal RNA 18s). The comparative threshold $\mathrm{C}(\mathrm{t})$ values were consistent in every sample. To ensure only gene amplification was measured, the $\mathrm{C}(\mathrm{t})$ value was set to ignore any aberrant fluorescence such as that from primer-dimer formation.

Analysis Using Liquid Chromatography-Tandem Mass Spectrometry. Liquid chromatography-tandem mass spectrometry analysis used a triple quadrupole API-4000 mass spectrometer with a Turbo V atmospheric pressure electrospray ionization source (AB SCIEX, Framingham, MA). All samples $(10 \mu \mathrm{l})$ were injected onto an ethylene bridged hybrid $\mathrm{C} 18$ column $(2.1 \times 30 \mathrm{~mm}$, $1.7 \mu \mathrm{m}$ ) and eluted by a mobile phase gradient specific for each test article (mobile phase A: $0.1 \%$ formic acid in water; mobile phase B: $0.1 \%$ formic acid in acetonitrile). The flow rate for all compounds was $1.0 \mathrm{ml} / \mathrm{min}$. The mass spectrometry conditions for all compounds were as follows: positive or negative ionization mode $\left(5.0 \mathrm{kV}\right.$ spray voltage); source temperature of $450{ }^{\circ} \mathrm{C}$ with multiple reactions monitoring specific for each analyte (Supplemental Table 2); and internal standard parent-product ion pairs. Peak areas of analyte and internal standard (labetalol $200 \mathrm{nM}$ ) and resulting ratios were quantified using MultiQuant Software (AB SCIEX).

Data Analysis. All activity data were completed in duplicate for three independent experiments $(N=3)$. Gene expression data were compared with an average of glyceraldehyde-3-phosphate dehydrogenase, glucuronidase beta, and ribosomal RNA 18s, and normalized to the control sample using the $\mathrm{C}(\mathrm{t})$ cycle method $\left[\mathrm{C}(\mathrm{t})=2^{-\Delta \Delta \mathrm{C}(\mathrm{t})}\right]$. Only compounds that produced a statistically significant $\mathrm{CL}_{\text {int }}$ were included in the analysis. The T-statistic was applied to determine the significance of the slope:

$$
T_{\text {slope }}=\frac{\text { Slope }}{\text { S.E.slope }}
$$

To determine the accuracy of the in vitro prediction following application of the regression equation the average fold error (AFE) was calculated between the observed and predicted in vivo $\mathrm{CL}_{\mathrm{int}}$ :

$$
\mathrm{AFE}=10^{(1 / N) \sum \log (\text { observed } / \text { predicted })}
$$

\section{Results}

\section{Activity Analysis: Incubations without Geltrex}

Day 1. Each donor was treated with a reference compound on day 1 postplating. Initial analysis assessed the activity of each donor following incubation with CM4000 and HepExtend without Geltrex. When incubated with CM4000 or HepExtend all three donors generated $\mathrm{CL}_{\text {int }}$ values following 30-hour compound treatment within 4-fold, except disopyramide and midazolam, which displayed $>5$-fold difference. However, these $\mathrm{CL}_{\text {int }}$ values were in agreement between $\mathrm{Hu} 8249$ and $\mathrm{Hu} 1753$ with the $>5$-fold discrepancy observed for Hu1824 (Fig. 1). The in vitro $\mathrm{CL}_{\text {int }}$ values and fold changes in $\mathrm{CL}_{\text {int }}$ for each donor and medium tested on assay days 1 and 5 are given for Hu1753 in Table 3, for Hu1824 in Table 4, and for Hu8249 in Table 5. Hu1824 displayed poor activity for CYP3A4-specific substrates. For each individual donor the $\mathrm{CL}_{\text {int }}$ values were within 2-fold for each compound regardless of which incubation medium was used (Tables 3-5).

Day 5. Following a 48-hour washout period, each donor was treated with a reference compound on day 5 postplating. Initial analysis assessed the activity of each donor following incubation with CM4000 and HepExtend without Geltrex. The $\mathrm{CL}_{\text {int }}$ values obtained following incubation with CM4000 were significantly decreased for Hu1753 

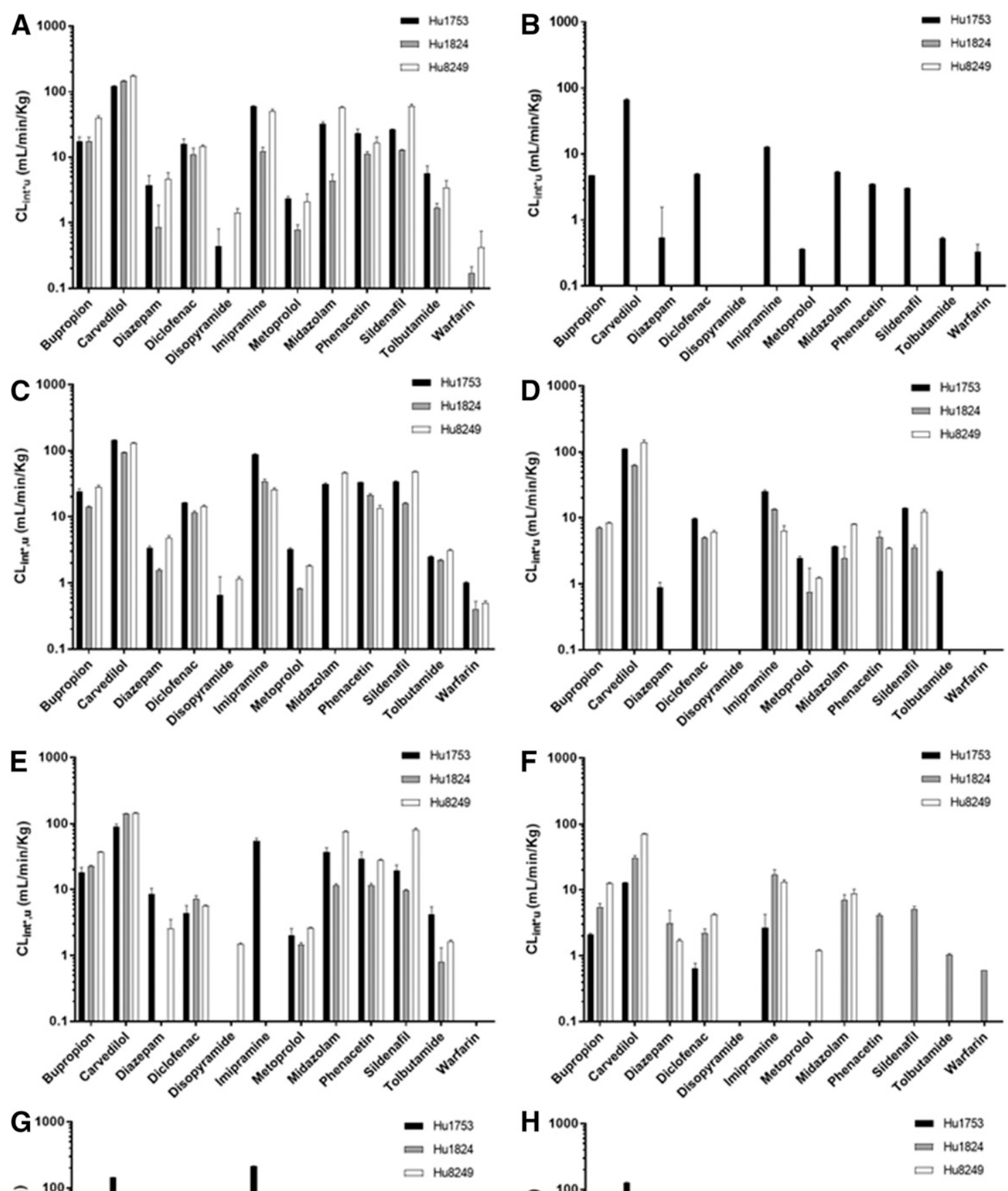

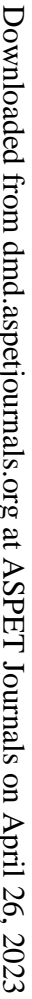
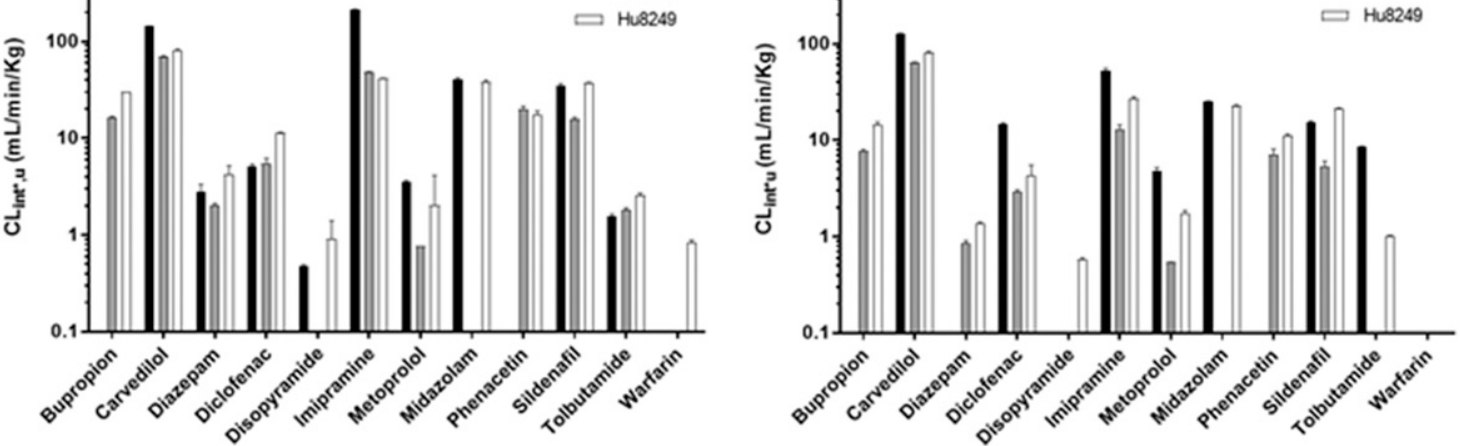

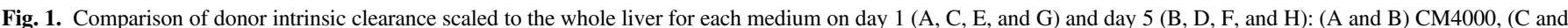

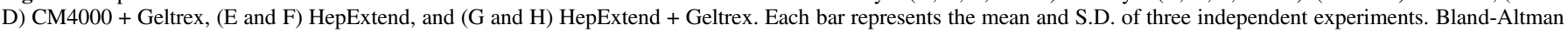

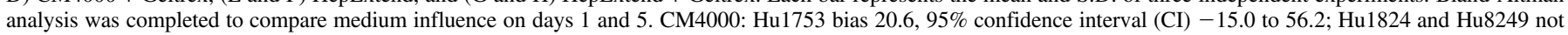

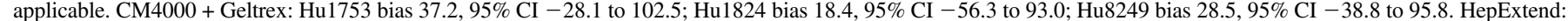

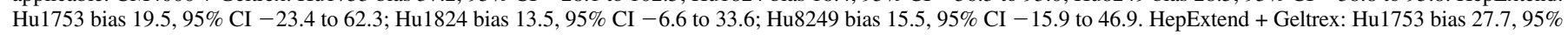
$\mathrm{CI}-89.9$ to 145.4 ; Hu1824 bias $9.6,95 \% \mathrm{CI}-12.6$ to 31.8 ; Hu8249 bias $7.4,95 \% \mathrm{CI}-6.0$ to 20.6. 

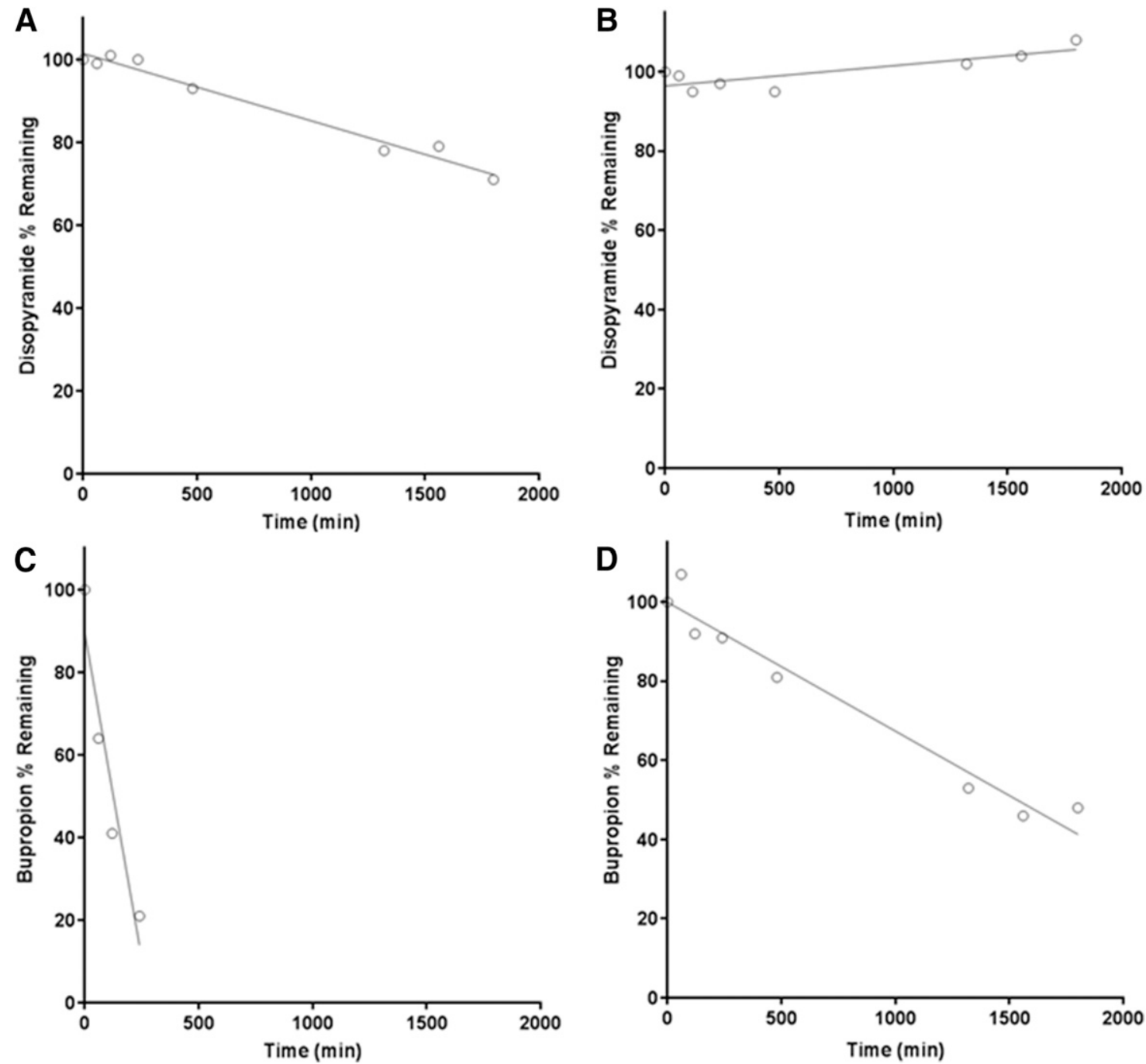

Fig. 2. Substrate depletion plot for Hu8249. Cells treated with disopyramide (A) and bupropion (C) with CM4000 + Geltrex on day 1 and media alone with disopyramide (B) and bupropion (D). The $\mathrm{CL}_{\text {int }}$ value for disopyramide with cells was $0.19 \mu \mathrm{l} / \mathrm{min} / 10^{6}$ cells, $P=1.5 \times 10^{-5}$; the $\mathrm{CL}_{\text {int }}$ value for disopyramide with media only was $<0.1 \mu \mathrm{l} / \mathrm{min} / 10^{6}$ cells, $P>0.05$. The $\mathrm{CL}_{\text {int }}$ value for bupropion with cells was $6.4 \mu \mathrm{l} / \mathrm{min} / 10^{6}$ cells, $P=4.6 \times 10^{-3}$; the $\mathrm{CL}_{\text {int }}$ value for bupropion with media only was $0.47 \mu 1 / \mathrm{min} / 10^{6}$ cells, $P=4.5 \times 10^{-6}$.

compared with the day 1 values (Tables 3). CM4000 was unable to maintain activity for 5 days for all compounds in donors Hu1824 and Hu 8249 (Fig. 1; Tables 4-5). In comparison, cells incubated with HepExtend generated a $\mathrm{CL}_{\text {int }}$ value for all three donors and the majority of compounds on day 5 . However, these values were $>2$-fold lower when compared with day 1 . In contrast to $\mathrm{Hu} 1753$ and $\mathrm{Hu} 8249$, $\mathrm{Hu} 1824$ activity was retained for $36 \%$ of compounds (within 2-fold) on day 5 when treated with HepExtend. For all donors treated with CM4000 or HepExtend, $\mathrm{a}>5$-fold decrease in the $\mathrm{CL}_{\text {int }}$ value was observed for $61 \%$ of compounds on day 5 compared with day 1 . Across all three donors, $94 \%$ of compounds displayed a $>2$-fold decrease in $\mathrm{CL}_{\text {int }}$ from day 1 to 5 ; of these, $76 \%$ displayed a $>5$-fold decrease in $\mathrm{CL}_{\text {int }}$.

\section{Activity Analysis: Incubations with Geltrex}

Day 1. Each donor was treated with a reference compound on day 1 postplating. Analysis assessed the activity of each donor following incubation with CM4000 and HepExtend with Geltrex. When incubated with CM4000 + Geltrex all three donors generated $\mathrm{CL}_{\text {int }}$ values following 30-hour compound treatment within 4-fold, except metoprolol, which displayed a 5-fold difference between donors. In comparison with CM4000 + Geltrex, activity observed across all three donors following
HepExtend + Geltrex incubation was relatively consistent. For all compounds and donors a 3-fold difference was observed (excluding imipramine and metoprolol). Hu1753 activity was greater for the CYP1A2 base, imipramine, when incubated with HepExtend + Geltrex compared with CM4000 + Geltrex: $20.6 \mu \mathrm{l} / \mathrm{min} / 10^{6}$ cells compared with $8.5 \mu \mathrm{l} / \mathrm{min} / 10^{6}$ cells, respectively.

Day 5. Following a 48-hour washout period, each donor was treated with a reference compound on day 5 postplating. Analysis assessed the activity of each donor following incubation with CM4000 and HepExtend with Geltrex. Inclusion of an overlay maintained the cells for a longer period such that the $\mathrm{CL}_{\mathrm{int}}$ value could be defined on day 5 (Fig. 1; Tables 3-5). Furthermore, as shown in Tables 3-5 the addition of Geltrex decreased the fold difference in $\mathrm{CL}_{\text {int }}$ between days 1 and 5 for CM4000 and HepExtend.

Following incubation with $\mathrm{CM} 4000+$ Geltrex, the $\mathrm{CL}_{\text {int }}$ values for $64 \%$ of compounds were decreased $>2$-fold for all three donors except carvedilol compared with day 1 (Fig. 1; Tables 3-5). Following incubation with $\mathrm{CM} 4000+$ Geltrex, the $\mathrm{CL}_{\text {int }}$ values were comparable on days 1 and 5 for $26 \%$ of compounds ( $\leq 2$-fold across all donors); an improvement of $20 \%$ when compared with medium without Geltrex. However, a $>5$-fold decrease was observed for $16 \%$ of compounds. 
TABLE 3

In vitro $\mathrm{CL}_{\text {int }}$ and the fold change in $\mathrm{CL}_{\text {int }}$ for Hu1753 in each medium tested on assay day 1 and 5

Stability results for Hul753 following incubation in different culture medium, where each value is the mean of $\mathrm{N}=3$. Values not determined were either due to cell death or the compound was not included in the analysis.

\begin{tabular}{|c|c|c|c|c|c|c|c|c|c|c|c|c|}
\hline \multirow{3}{*}{ Compound } & \multicolumn{12}{|c|}{ Hu1753 ( $\mu \mathrm{l} / \mathrm{min} / 10^{6}$ cells $)$} \\
\hline & \multicolumn{3}{|c|}{$\mathrm{CM} 4000 \mathrm{CL}_{\text {int }}$} & \multicolumn{3}{|c|}{ HepExtend $\mathrm{CL}_{\text {int }}$} & \multicolumn{3}{|c|}{$\mathrm{CM} 4000+$ Geltrex $\mathrm{CL}_{\text {int }}$} & \multicolumn{3}{|c|}{ HepExtend + Geltrex $\mathrm{CL}_{\text {int }}$} \\
\hline & Day 1 & Day 5 & Fold Shift & Day 1 & Day 5 & Fold Shift & Day 1 & Day 5 & Fold Shift & Day 1 & Day 5 & Fold Shift \\
\hline Bupropion & 3.3 & 0.9 & -3.7 & 3.4 & 0.4 & -8.6 & 4.6 & ND & NA & ND & ND & NA \\
\hline Carvedilol & 12.1 & 6.7 & -1.8 & 8.9 & 1.3 & -6.9 & 14.5 & 11.1 & -1.3 & 14.3 & 12.7 & -1.1 \\
\hline Diazepam & 0.8 & 0.1 & -6.9 & 1.8 & $*$ & NA & 0.7 & 0.2 & -3.8 & 0.6 & $*$ & NA \\
\hline Diclofenac & 4.5 & 1.4 & -3.2 & 1.3 & 0.2 & -6.9 & 4.7 & 2.8 & -1.7 & 1.5 & 4.2 & 2.9 \\
\hline Disopyramide & 0.10 & $*$ & NA & $*$ & $*$ & NA & 0.1 & $*$ & NA & 0.1 & $*$ & NA \\
\hline Imipramine & 5.8 & 1.0 & -5.6 & 5.3 & 0.2 & -24.5 & 8.5 & 2.0 & -4.2 & 20.6 & 4.3 & -4.8 \\
\hline Metoprolol & 0.6 & 0.1 & -6.5 & 0.5 & $*$ & NA & 0.9 & 0.7 & -1.3 & 0.9 & 1.3 & 1.4 \\
\hline Midazolam & 5.3 & 0.9 & -6.0 & 6.1 & $*$ & NA & 5.1 & 0.6 & -8.4 & 6.7 & 4.1 & -1.6 \\
\hline Sildenafil & 5.5 & 0.6 & -8.8 & 4.0 & $*$ & NA & 7.1 & 2.9 & -2.4 & 7.3 & 3.2 & -2.3 \\
\hline Tolbutamide & 1.7 & 0.2 & -10.6 & 1.3 & $*$ & NA & 0.8 & 0.5 & -1.6 & 0.5 & 2.6 & 5.5 \\
\hline Warfarin & $*$ & 0.1 & NA & $*$ & $*$ & NA & 0.3 & $*$ & NA & $*$ & $*$ & NA \\
\hline
\end{tabular}

NA, not applicable; ND, not determined.

*Represents no statistically significant $\mathrm{CL}_{\text {int }}$

A $>5$-fold decrease in $\mathrm{CL}_{\text {int }}$ was observed for midazolam in $\mathrm{Hu} 1753$ and $\mathrm{Hu} 8249$ and tolbutamide for Hu1824. The decrease was also observed at the mRNA level (Fig. 4).

Following incubation with HepExtend + Geltrex, 50\% of compounds across all three donors produced $\mathrm{CL}_{\text {int }}$ values within 2-fold on days 1 and 5 (across all three donors) and only 10\% displayed a $>5$-fold decrease in $\mathrm{CL}_{\text {int }}$ on day 5. For Hu8249 and Hu1753, HepExtend + Geltrex maintained activity for $73 \%$ and $64 \%$ of compounds (within 2-fold), respectively. In comparison, activity for $\mathrm{Hu} 1824$ was only retained for $36 \%$ of compounds (within 2-fold). In comparison with all other donors and culture mediums, Hu8249 produced the most consistent and reproducible $\mathrm{CL}_{\text {int }}$ values for all experiments $(N=3)$ when incubated with HepExtend + Geltrex (Fig. 1; Tables 3-5). The same trend was observed for the mRNA expression (Fig. 4).

\section{mRNA Expression Analysis}

Gene expression was assessed on days 1 and 5 following incubation with the medium. Expression for all genes when incubated with HepExtend + Geltrex on days 1 and 5 was greater than the reference point of 1 (CM4000 + Geltrex), where 1 is equal gene expression (Fig. 4, $\mathrm{A}$ and $\mathrm{B})$. Therefore, mRNA expression for all 45 genes was maintained.
In comparison with CM4000 \pm Geltrex, HepExtend + Geltrex displayed a higher level of gene expression on day 1, particularly for the P450s, nuclear receptors, and UDP-glucuronosyltransferases (UGTs) (Fig. 4A). On day 5, the mRNA expression of the hepatic markers (e.g., albumin), nutritional/ metabolic markers (e.g., HMGCS2) (Rescigno et al., 2018), transporters, and UGTs were consistent with expression levels on day 1 (Fig. 4B). When compared with Hu1753 and Hu1824, Hu8249 was superior in expressing and subsequently retaining its mRNA expression on days 1 and 5 when incubated with HepExtend + Geltrex (Fig. 4, C-F). In contrast, when incubated with HepExtend + Geltrex Hu1753 and Hu1824 expressed higher levels of CYP2C19 compared with Hu8249 (Fig. 4C).

\section{Comparison of In Vitro to In Vivo}

In comparison with Hu1753 and Hu1824, activity and mRNA expression for Hu8249 were superior when incubated with HepExtend + Geltrex on days 1 and 5. This observation justified the selection of this donor to generate a comparison of in vitro and in vivo data on day 1 (Fig. 3).

Similar to previous studies (Sohlenius-Sternbeck et al., 2012), the in vitro data underpredicted the in vivo $\mathrm{CL}$; hence, a regression correction was required (Fig. 3B). Following regression correction, human hepatic in vivo CL was predicted within 3 -fold for $83 \%$ of

TABLE 4

In vitro $\mathrm{CL}_{\mathrm{int}}$ and the fold change in $\mathrm{CL}_{\mathrm{int}}$ for $\mathrm{Hu} 1824$ in each medium tested on assay day 1 and 5

Stability results for Hul 824 following incubation in different culture medium, where each value is the mean of $\mathrm{N}=3$. Values not determined were either due to cell death or the compound was not included in the analysis.

\begin{tabular}{|c|c|c|c|c|c|c|c|c|c|c|c|c|}
\hline \multirow{3}{*}{ Compound } & \multicolumn{12}{|c|}{ Hu1824 ( $\mu \mathrm{l} / \mathrm{min} / 10^{6}$ cells $)$} \\
\hline & \multicolumn{3}{|c|}{$\mathrm{CM} 4000 \mathrm{CL}_{\mathrm{int}}$} & \multicolumn{3}{|c|}{ HepExtend $\mathrm{CL}_{\text {int }}$} & \multicolumn{3}{|c|}{$\mathrm{CM} 4000+$ Geltrex $\mathrm{CL}_{\text {int }}$} & \multicolumn{3}{|c|}{ HepExtend + Geltrex $\mathrm{CL}_{\mathrm{int}}$} \\
\hline & Day 1 & Day 5 & Fold Shift & Day 1 & Day 5 & Fold Shift & Day 1 & Day 5 & Fold Shift & Day 1 & Day 5 & Fold Shift \\
\hline Bupropion & 3.3 & $*$ & NA & 4.3 & 1.04 & -4.2 & 2.7 & 1.3 & -2.0 & 3.1 & 1.5 & -2.1 \\
\hline Carvedilol & 14.6 & $*$ & NA & 14.2 & 3.10 & -4.6 & 9.3 & 6.3 & -1.5 & 6.9 & 6.4 & -1.1 \\
\hline Diazepam & 0.2 & $*$ & NA & $*$ & 0.65 & NA & 0.3 & $*$ & NA & 0.4 & 0.2 & -2.4 \\
\hline Diclofenac & 3.2 & $*$ & NA & 2.1 & 0.64 & -3.2 & 3.4 & 1.4 & -2.4 & 1.6 & 0.8 & -1.9 \\
\hline Disopyramide & $<0.1$ & $*$ & NA & $*$ & $*$ & NA & $*$ & $*$ & NA & NA & $*$ & NA \\
\hline Imipramine & 1.0 & $*$ & NA & ND & 1.40 & NA & 2.8 & 1.1 & -2.5 & 3.9 & 1.1 & -3.7 \\
\hline Metoprolol & 0.2 & $*$ & NA & 0.4 & $*$ & NA & 0.2 & 0.2 & -1.1 & 0.2 & 0.1 & -1.4 \\
\hline Midazolam & 0.7 & $*$ & NA & 1.9 & 1.17 & -1.6 & ND & 0.4 & NA & ND & $*$ & NA \\
\hline Sildenafil & 2.7 & $*$ & NA & 2.0 & 1.06 & -1.9 & 3.4 & 0.7 & -4.6 & 3.3 & 1.1 & -3.0 \\
\hline Tolbutamide & 0.5 & $*$ & NA & 0.2 & 0.31 & 1.3 & 0.7 & $*$ & NA & 0.5 & $*$ & NA \\
\hline Warfarin & 0.1 & $*$ & NA & $*$ & 0.18 & NA & 0.1 & $*$ & NA & $*$ & $*$ & NA \\
\hline
\end{tabular}

NA, not applicable; ND, not determined.

*Represents no statistically significant $\mathrm{CL}_{\text {int }}$ 
TABLE 5

In vitro $\mathrm{CL}_{\text {int }}$ and the fold change in $\mathrm{CL}_{\text {int }}$ for Hu8249 in each medium tested on assay day 1 and 5

Stability results for Hu8249 following incubation in different culture medium. Where, each value is the mean of $\mathrm{N}=3$. Values not determined were either due to cell death or the compound was not included in the analysis.

\begin{tabular}{|c|c|c|c|c|c|c|c|c|c|c|c|c|}
\hline \multirow{3}{*}{ Compound } & \multicolumn{12}{|c|}{ Hu8249 ( $\mu \mathrm{l} / \mathrm{min} / 10^{6}$ cells $)$} \\
\hline & \multicolumn{3}{|c|}{$\mathrm{CM} 4000 \mathrm{CL}_{\text {int }}$} & \multicolumn{3}{|c|}{ HepExtend $\mathrm{CL}_{\text {int }}$} & \multicolumn{3}{|c|}{$\mathrm{CM} 4000+$ Geltrex $\mathrm{CL}_{\text {int }}$} & \multicolumn{3}{|c|}{ HepExtend + Geltrex $\mathrm{CL}_{\text {int }}$} \\
\hline & Day 1 & Day 5 & Fold Shift & Day 1 & Day 5 & Fold Shift & Day 1 & Day 5 & Fold Shift & Day 1 & Day 5 & Fold Shift \\
\hline Bupropion & 7.5 & $*$ & NA & 7.1 & 2.41 & -2.9 & 5.4 & 1.6 & -3.3 & 5.7 & 2.7 & -2.1 \\
\hline Carvedilol & 17.4 & $*$ & NA & 14.6 & 7.13 & -2.1 & 13.1 & 13.9 & 1.1 & 8.2 & 8.1 & -1.0 \\
\hline Diazepam & 1.0 & $*$ & NA & 0.5 & 0.35 & -1.5 & 1.0 & $*$ & NA & 0.9 & 0.3 & -3.0 \\
\hline Diclofenac & 4.2 & $*$ & NA & 1.6 & 1.21 & -1.4 & 4.2 & 1.8 & -2.4 & 3.3 & 1.2 & -2.7 \\
\hline Disopyramide & 0.3 & $*$ & NA & $*$ & $*$ & NA & 0.3 & $*$ & NA & 0.2 & 0.1 & -1.6 \\
\hline Ethinyl estradiol & ND & ND & NA & ND & ND & ND & ND & ND & ND & 3.3 & ND & NA \\
\hline Imipramine & 4.9 & $*$ & NA & ND & 1.07 & NA & 2.5 & 0.5 & -4.8 & 4.0 & 2.2 & -1.8 \\
\hline Metoprolol & 0.6 & $*$ & NA & 0.7 & 0.32 & -2.2 & 0.5 & 0.3 & -1.5 & 0.5 & 0.5 & -1.2 \\
\hline Midazolam & 9.4 & $*$ & NA & 12.4 & 1.43 & -8.6 & 7.6 & 1.3 & -5.7 & 6.2 & 3.7 & -1.7 \\
\hline Sildenafil & 12.3 & $*$ & NA & 16.8 & $*$ & NA & 10.0 & 2.6 & -3.9 & 7.7 & 4.4 & -1.8 \\
\hline Tolbutamide & 1.0 & $*$ & NA & 0.5 & $*$ & NA & 0.9 & $*$ & NA & 0.8 & 0.3 & -2.5 \\
\hline Warfarin & 0.1 & $*$ & NA & $*$ & $*$ & NA & 0.1 & $*$ & NA & 0.2 & $*$ & NA \\
\hline
\end{tabular}

NA, not applicable; ND, not determined.

*Represents no statistically significant $\mathrm{CL}_{\text {int }}$

compounds tested for Hu8249, with an AFE of 2.2. No significant difference was observed between values as determined by Bland-Altman analysis (bias, $8 \times 10^{-4}$; 95\% confidence intervals, -0.82 and 0.82 ).

Despite the chemical instability observed in media-only incubations (Fig. 2, C and D), in vitro data generated for bupropion correlated with the in vivo observation (Fig. 3). The hepatocyte $\mathrm{CL}_{\text {int }}$ was greater than 10 -fold higher than the media-only $\mathrm{CL}_{\mathrm{int}}$, suggesting the impact of chemical instability on the in vivo $\mathrm{CL}_{\text {int }}$ prediction is negligible. However, the observation is nonetheless noteworthy, and a worthwhile consideration in the context of ensuring accuracy in human predictions.

Diclofenac and tolbutamide fell outside the 2-fold lines of agreement (>3-fold) (Fig. 3B). These outliers have been reported previously (Hewitt and Utesch, 2004; Chan et al., 2013). Cryopreservation techniques have been noted to alter CYP2C9 activity and this could contribute to the offset observed for tolbutamide (Hewitt and Utesch, 2004).

\section{Discussion}

Metabolically stable compounds present a challenge in drug discovery due to the quantification limits of existing hepatocyte suspension assays (Smith et al., 2012). Defining human hepatic metabolic $\mathrm{CL}_{\text {int }}$ in vitro is key for scaling to in vivo human CL; arguably the key parameter in predicting human PK and estimating efficacious dose (Grime et al., 2013). Noting this limitation, work herein was focused on optimizing an assay to define the $\mathrm{CL}_{\text {int }}$ values for metabolically stable project compounds.

Following a review of the literature (Lau et al., 2002; Novik et al., 2010; Di et al., 2012; Smith et al., 2012; Chan et al., 2013; Hutzler et al., 2015), plated PHHs were chosen as a method for determining human $\mathrm{CL}_{\text {int }}$ values less than $3 \mu \mathrm{l} / \mathrm{min} / 10^{6}$ cells. The media supplements HepExtend and Geltrex were compared with the widely used PHH maintenance medium, CM4000, in order to determine their effectiveness in extending P450 function beyond the reported 10 hours
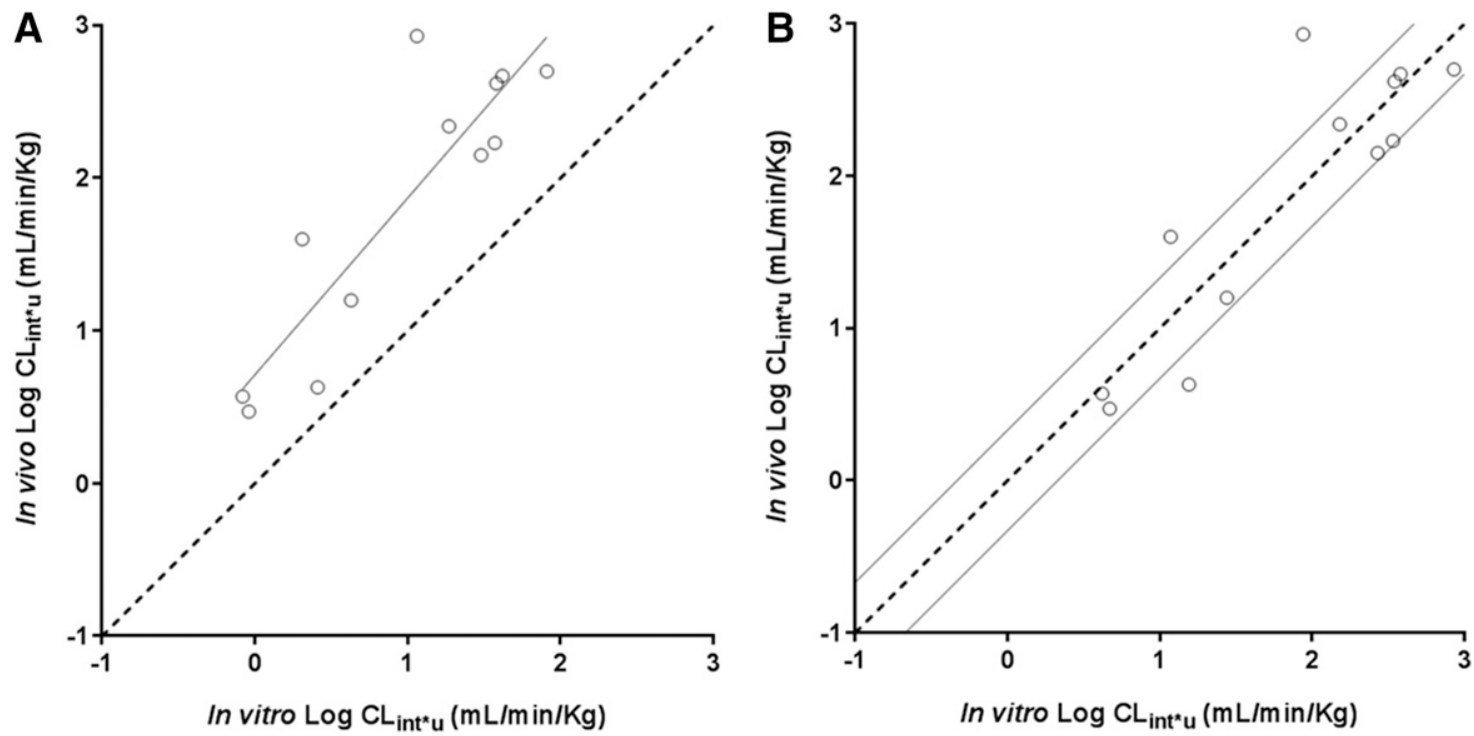

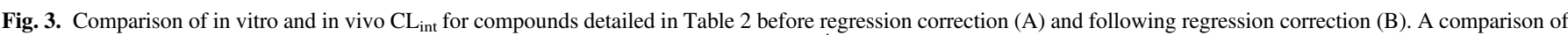

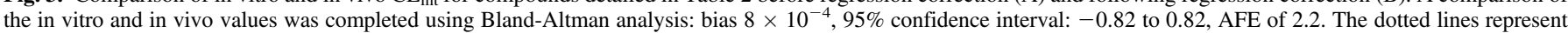
unity in both plots and the solid lines represent the regression line in (A) and \pm 2 -fold offset from unity in (B). 
A

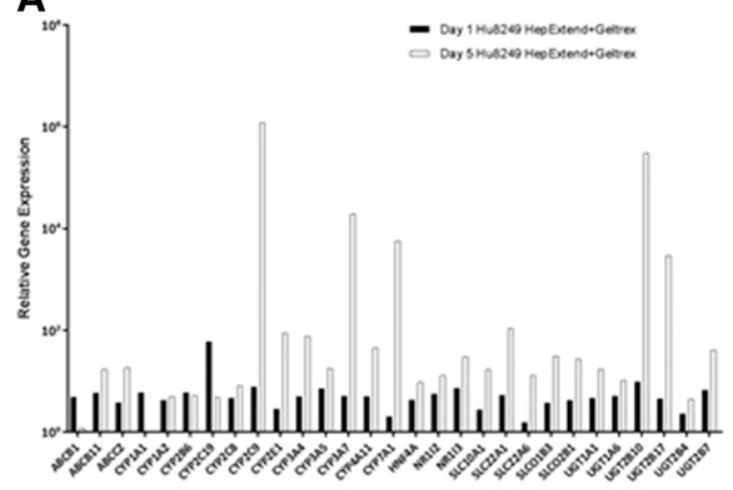

C

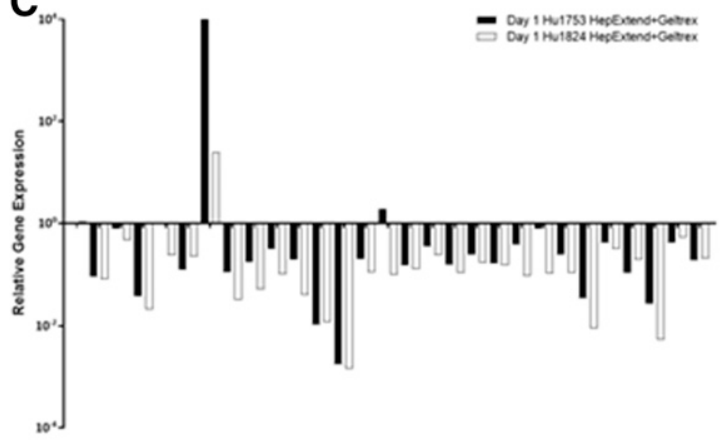

A

E

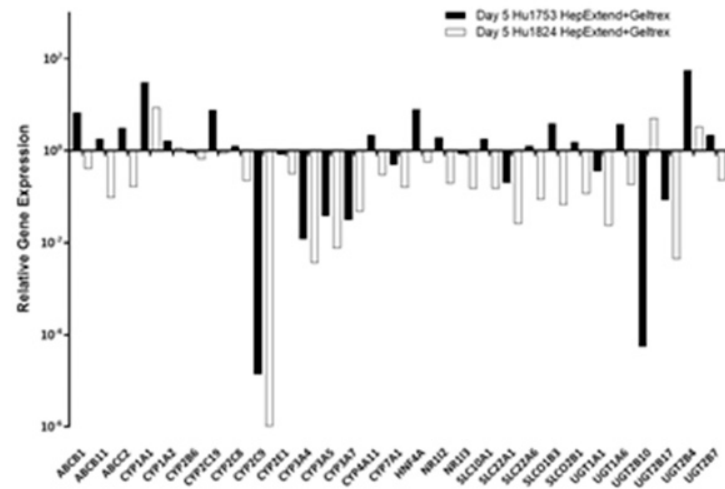

B

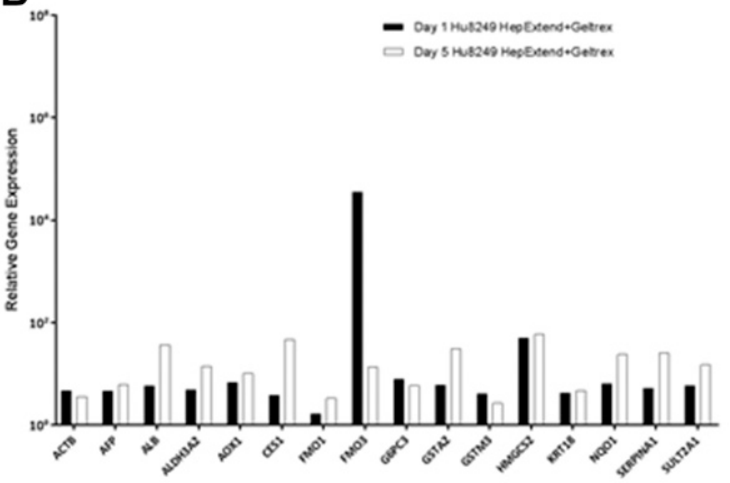

D

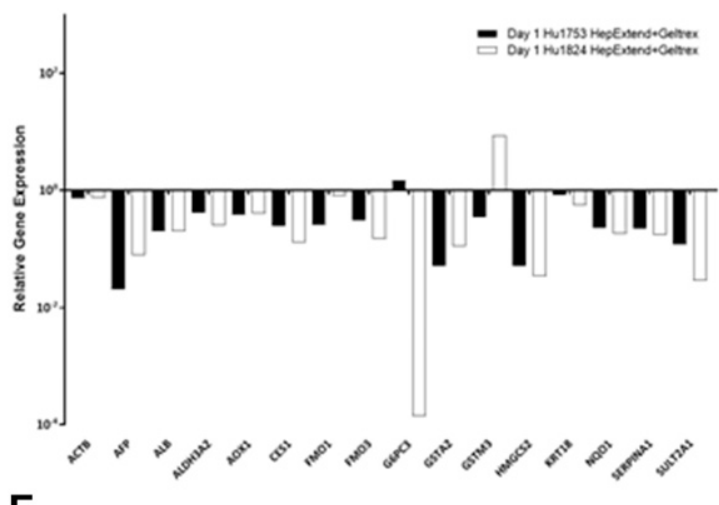

$\mathbf{F}$

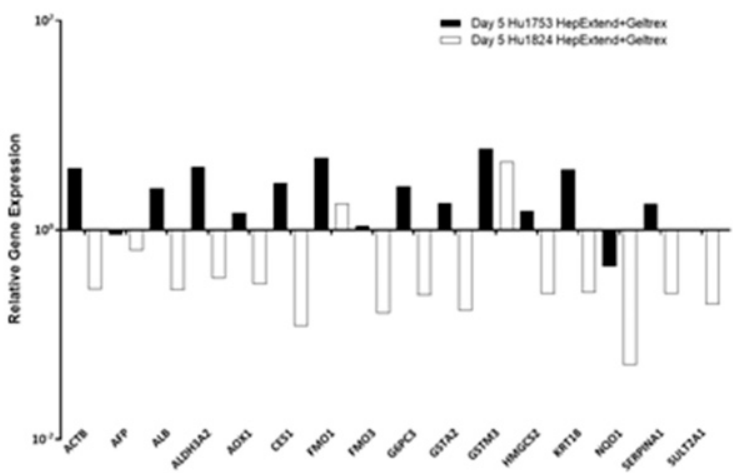

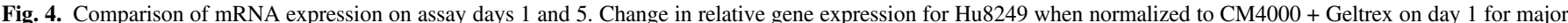

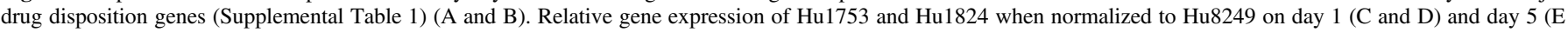
and F) for major drug disposition genes (Supplemental Table 1).

(Smith et al., 2012; Bonn et al., 2016). Additionally, the utility of the supplements plus an overlay for prolonging cell function after 5 days in culture was assessed.

In contrast to previous work (Hutzler et al., 2015; Bonn et al., 2016), reproducible linear $\mathrm{CL}_{\mathrm{int}}$ profiles for disopyramide and warfarin were generated throughout the analysis. A no cell control further confirmed the robustness of the assay and the ability to generate a statistically significant $\mathrm{CL}_{\text {int }}$ of $0.1 \mu \mathrm{l} / \mathrm{min} / 10^{6}$ cells (Fig. 1).

Geltrex prolonged metabolizing enzyme function, with day $5 \mathrm{CL}_{\mathrm{int}}$ values significantly lower than day 1 values in the assays without Geltrex $\left(76 \%\right.$ and $61 \%$ displayed a $>5$-fold decrease in $\mathrm{CL}_{\text {int }}$ for reference compounds with CM4000 and HepExtend, respectively). An additional improvement in maintaining metabolic CL rates was observed with the presence of HepExtend. Incubations containing both supplements generated $\mathrm{CL}_{\mathrm{int}}$ values most comparable to day $1\left(50 \%\right.$ of $\mathrm{CL}_{\mathrm{int}}$ values were within 2-fold for all three donors).
The effectiveness of the supplement was donor specific, with Hu8249 benefitting the most (Fig. 2; Tables 3-5). For example, 91\% of compounds tested on both days deviated less than 3 -fold in the presence of both media supplements. This finding presents discovery teams with the potential to use the same hepatocyte cultures for two separate assays, offering both cost and time-saving benefits. However, characterization is required to ensure hepatocyte function is maintained for individual donors for up to 5 days, while the potential impact of suicide inhibitors should also be considered.

At a gene level, expression of uptake and efflux transporters, P450s, UGTs, and nuclear receptors in Hu8249 were enhanced on both days 1 and 5 when HepExtend was in the culture media (Fig. 4). This highlights the functional benefits of including HepExtend and Geltrex in monolayer cultures. It is hypothesized that HepExtend provides additional hepatocyte nutrients for improved function, while Geltrex provides the support for enhanced cell-to-cell contact and subsequent morphology. 
$\mathrm{CL}_{\text {int }}$ was successfully determined for low-turnover compounds, with statistically significant values $(P<0.05)$ measured repeatedly for disopyramide, diazepam, metoprolol, and tolbutamide (Fig. 2; Tables 3-5). Some laboratories define the LLOQ by extrapolating the incubation time; for example, 10-hour incubation can produce an LLOQ $\mathrm{CL}_{\text {int }}$ of 0.5 $\mu \mathrm{l} / \mathrm{min} / 10^{6}$ cells (Bonn et al., 2016). Alternatively, LLOQ can be defined by the lowest possible statistically significant $\mathrm{CL}_{\text {int }}$ as determined from T-statistical analysis (e.g., 30-hour incubation $=0.1 \mu \mathrm{l} / \mathrm{min} / 10^{6}$ cells, as defined herein). Furthermore, the log-linear substrate depletion profiles remain linear for up to 30 hours (Fig. 1). Consequently, the LLOQ of this assay is lower than other laboratories have reported using plated PHHs (Bonn et al., 2016). Furthermore, Hutzler et al. (2015) suggested that incubations for CL estimation should be limited to 24 hours or less. A key differentiator between our assay and others is the inclusion of additional supplements in the maintenance media.

After 1 day in culture, PHH activity was similar for each donor and each culture medium (Tables 3-5). This demonstrated that metabolizing enzyme function and activity were not impaired by the presence of HepExtend and/or Geltrex when the cells were used within 48 hours of plating. Additionally, for Hu8249 the mRNA analysis confirmed an increase in mRNA expression for all 45 genes (Fig. 4).

Out of the three donors characterized, Hu1824 had noticeably lower activity than Hu1753 and Hu8249, particularly for CYP3A4 and its substrate midazolam. This may be explained at a gene level, with lower quantities of mRNA quantifiable on days 1 and 5 in comparison with Hu 1753 and Hu8249 (Fig. 4). These observations illustrate the importance of donor characterization, and the requirement to batch test donors prior to use in drug discovery (Hutzler et al., 2014), and define a donorspecific regression (Sohlenius-Sternbeck et al., 2012).

Extrapolation of in vitro stability data using physiologic scaling parameters, including correction for the fraction unbound in the incubation (Austin et al., 2005; Kilford et al., 2008), and the restricted well-stirred model resulted in a systematic underprediction of CL. This systematic bias was removed by applying an empirical regression correction to the in vitro data for the defined set of reference compounds (Fig. 3). Following regression correction, human hepatic in vivo $\mathrm{CL}$ was predicted within 3 -fold for $83 \%$ of compounds tested for the three human donors, with an AFE of 2.2. Subsequently, applying the same regression corrections to drug discovery compounds can improve CL predictions from in vitro metabolism data, and ultimately lead to improved PK predictions (Riley et al., 2005; Sohlenius-Sternbeck et al., 2012). However, it should be noted that the root cause of the inaccuracies inherent in the regression approach remain undefined (Bowman and Benet, 2016).

Where possible, all human donors should provide representation of all drug-metabolizing activity. For example, Hu1824 demonstrated low CYP3A4 activity, which would result in this donor underpredicting human $\mathrm{CL}$ for all compounds where the fraction metabolized by CYP3A4 is significant. Thus, a regression correction would not militate against the reduced activity of the isoform. This observation reinforces the importance of characterizing human donors prior to use in drug discovery screens. Additionally, underpredictions of in vivo CL can be accentuated in PHHs when compounds are highly cleared, possibly due to rate-limited uptake of compound into static flow hepatocyte monolayers, and the reduced surface area for drug diffusion relative to suspension assays, impacting apparent enzyme kinetics (Hutzler et al., 2015).

As an alternative to single donors, development of pooled human donors suitable for plating have received much attention, with the purpose of improving human CL predictions by overcoming population differences. Pools of human hepatocytes in suspension cultures have been widely used (Shibata et al., 2002; Riley et al., 2005; Grime and Riley, 2006; Sohlenius-Sternbeck et al., 2012; Hutzler et al., 2015), while historically pooled donors in plated monocultures have proved far more challenging, with some donors not amenable to plating (Hutzler et al., 2015). Technology is continuing to improve in this area with suppliers now offering plateable donor pools verified for phase I enzyme activity and plating efficiency. The authors acknowledge the value of these products, not only to account for poor metabolizers, but also for variances driven by uptake rates of transporter substrates. However, the robust nature of our validation for single human donors, including the use of isoform-specific markers and donor-specific regression correction, provides us with confidence in our chosen donor(s) and their utility for providing physiologically relevant hepatic metabolism rates.

For this validation, the compound selection focused on representing a range of $\mathrm{P} 450$ isoforms. While $\mathrm{P} 450$ s are responsible for metabolic elimination of the majority of drugs currently on the market (Williams et al., 2004), we recognize the importance of not limiting donor validations solely to P450s. UGTs also constitute an important group of conjugating enzymes, and representative markers including ethinyl estradiol (UGT1A1) and zidovudine (UGT2B7) have since been included in our validation sets (full data set not shown).

After applying the regression correction (Fig. 3), diclofenac and tolbutamide were identified as outliers (greater than 3-fold outside the line of unity). Pertinent to diclofenac, literature reports suggest variance in CL predictions can be accentuated for high CL compounds (Hutzler et al., 2015). Furthermore, cryopreservation techniques have been noted to alter CYP2C9 activity and this could contribute to the offsets observed for both compounds (Hewitt and Utesch, 2004; Brown et al., 2007).

In summary, a plated hepatocyte assay capable of quantifying stable compounds and thus improving the precision of human in vivo CL predictions has been developed. This assay enables generation of linear substrate depletion profiles for up to 30 hours, providing reliable $\mathrm{CL}_{\text {int }}$ values as low as $0.1 \mu \mathrm{l} / \mathrm{min} / 10^{6}$ cells. With the addition of a regression correction, in vivo CL predictions within 3-fold of observed CL for 83\% of our diverse substrate selection were derived. More work is required to validate the approach for non-P450 metabolic CL mechanisms. With the inclusion of media supplements HepExtend and Geltrex, the same hepatocyte cultures have the potential to be used for two separate assays. With a cautionary note of suicide inhibitors for new chemical entities, this assay could offer significant cost and time-saving benefits to drug discovery groups.

\section{Acknowledgments}

We acknowledge Thermo Fisher Scientific Life Technologies for providing the primary human hepatocytes.

\section{Authorship Contributions}

Participated in research design: Barton, Riley, Williamson.

Conducted experiments: Lancett, Williamson.

Performed data analysis: Lancett, Williamson.

Wrote or contributed to the writing of the manuscript: Barton, Lancett, Riley, Williamson.

\section{References}

Austin RP, Barton P, Mohmed S, and Riley RJ (2005) The binding of drugs to hepatocytes and its relationship to physicochemical properties. Drug Metab Dispos 33:419-425.

Bonn B, Svanberg P, Janefeldt A, Hultman I, and Grime K (2016) Determination of human hepatocyte intrinsic clearance for slowly metabolized compounds: comparison of a primary hepatocyte/stromal cell co-culture with plated primary hepatocytes and HepaRG. Drug Metab Dispos 44:527-533.

Bowman CM and Benet LZ (2016) Hepatic clearance predictions from in vitro-in vivo extrapolation and the biopharmaceutics drug disposition classification system. Drug Metab Dispos 44: $1731-1735$.

Brown HS, Griffin M, and Houston JB (2007) Evaluation of cryopreserved human hepatocytes as an alternative in vitro system to microsomes for the prediction of metabolic clearance. Drug Metab Dispos 35:293-301.

Chan TS, Yu H, Moore A, Khetani SR, and Tweedie D (2013) Meeting the challenge of predicting hepatic clearance of compounds slowly metabolized by cytochrome P450 using a novel hepatocyte model, hepatoPac. Drug Metab Dispos 41:2024-2032. 
Chen GC, Ramanathan VS, Law D, Funchain P, Chen GC, French S, Shlopov B, Eysselein V, Chung D, Reicher S, et al. (2010) Acute liver injury induced by weight-loss herbal supplements. World J Hepatol 2:410-415.

Chen YF, Tseng CY, Wang HW, Kuo HC, Yang VW, and Lee OK (2012) Rapid generation of mature hepatocyte-like cells from human induced pluripotent stem cells by an efficient three-step protocol. Hepatology 55:1193-1203.

De Bruyn T, Chatterjee S, Fattah S, Keemink J, Nicolaï J, Augustijns P, and Annaert P (2013) Sandwich-cultured hepatocytes: utility for in vitro exploration of hepatobiliary drug disposition and drug-induced hepatotoxicity. Expert Opin Drug Metab Toxicol 9:589-616.

Di L, Atkinson K, Orozco CC, Funk C, Zhang H, McDonald TS, Tan B, Lin J, Chang C and Obach RS (2013) In vitro-in vivo correlation for low-clearance compounds using hepatocyte relay method. Drug Metab Dispos 41:2018-2023.

Di L and Obach RS (2015) Addressing the challenges of low clearance in drug research. AAPS J 17:352-357.

Di L, Trapa P, Obach RS, Atkinson K, Bi YA, Wolford AC, Tan B, McDonald TS, Lai Y, and Tremaine LM (2012) A novel relay method for determining low-clearance values. Drug Metab Dispos 40:1860-1865.

Godoy P, Hewitt NJ, Albrecht U, Andersen ME, Ansari N, Bhattacharya S, Bode JG, Bolleyn J, Borner C, Böttger J, et al. (2013) Recent advances in 2D and 3D in vitro systems using primary hepatocytes, alternative hepatocyte sources and non-parenchymal liver cells and their use in investigating mechanisms of hepatotoxicity, cell signaling and ADME. Arch Toxicol 87: $1315-1530$.

Grime K and Riley RJ (2006) The impact of in vitro binding on in vitro-in vivo extrapolations, projections of metabolic clearance and clinical drug-drug interactions. Curr Drug Metab 7: 251-264.

Grime KH, Barton P, and McGinnity DF (2013) Application of in silico, in vitro and preclinical pharmacokinetic data for the effective and efficient prediction of human pharmacokinetics. Mo Pharm 10:1191-1206.

Hewitt NJ and Utesch D (2004) Cryopreserved rat, dog and monkey hepatocytes: measurement of drug metabolizing enzymes in suspensions and cultures. Hum Exp Toxicol 23:307-316.

Hutzler JM, Ring BJ, and Anderson SR (2015) Low-turnover drug molecules: a current challenge for drug metabolism scientists. Drug Metab Dispos 43:1917-1928.

Hutzler JM, Yang YS, Brown C, Heyward S, and Moeller T (2014) Aldehyde oxidase activity in donor-matched fresh and cryopreserved human hepatocytes and assessment of variability in 75 donors. Drug Metab Dispos 42:1090-1097.

Keemink J, Oorts M, and Annaert P (2015) Primary hepatocytes in sandwich culture, in Protocols in In Vitro Hepatocyte Research pp 175-188, Springer, New York.

Khetani SR and Bhatia SN (2008) Microscale culture of human liver cells for drug development. Nat Biotechnol 26:120-126.

Kilford PJ, Gertz M, Houston JB, and Galetin A (2008) Hepatocellular binding of drugs: correction for unbound fraction in hepatocyte incubations using microsomal binding or drug lipophilicity data. Drug Metab Dispos 36:1194-1197.

Kratochwil NA, Meille C, Fowler S, Klammers F, Ekiciler A, Molitor B, Simon S, Walter I, McGinnis C, Walther J, et al. (2017) Metabolic profiling of human long-term liver models and hepatic clearance predictions from in vitro data using nonlinear mixed-effects modeling. AAPS $J$ 19:534-550.

Lau YY, Sapidou E, Cui X, White RE, and Cheng KC (2002) Development of a novel in vitro model to predict hepatic clearance using fresh, cryopreserved, and sandwich-cultured hepatocytes. Drug Metab Dispos 30:1446-1454.
Levy G, Bomze D, Heinz S, Ramachandran SD, Noerenberg A, Cohen M, Shibolet O, Sklan E, Braspenning J, and Nahmias Y (2015) Long-term culture and expansion of primary human hepatocytes. Nat Biotechnol 33:1264-1271.

Novik E, Maguire TJ, Chao P, Cheng KC, and Yarmush ML (2010) A microfluidic hepatic coculture platform for cell-based drug metabolism studies. Biochem Pharmacol 79:1036-1044

Obach RS, Lombardo F, and Waters NJ (2008) Trend analysis of a database of intravenous pharmacokinetic parameters in humans for 670 drug compounds. Drug Metab Dispos 36: $1385-1405$.

Peng CC, Doshi U, Prakash C, and Li AP (2016) A novel plated hepatocyte relay assay (PHRA) for in vitro evaluation of hepatic metabolic clearance of slowly metabolized compounds. Drug Metab Lett 10:3-15.

Rashid ST, Corbineau S, Hannan N, Marciniak SJ, Miranda E, Alexander G, Huang-Doran I, Griffin J, Ahrlund-Richter L, Skepper J, et al. (2010) Modeling inherited metabolic disorders of the liver using human induced pluripotent stem cells. J Clin Invest 120:3127-3136.

Rescigno T, Capasso A, and Tecce MF (2018) Involvement of nutrients and nutritional mediators in mitochondrial 3-hydroxy-3-methylglutaryl-CoA synthase gene expression. J Cell Physiol 233:3306-3314

Riley RJ, McGinnity DF, and Austin RP (2005) A unified model for predicting human hepatic metabolic clearance from in vitro intrinsic clearance data in hepatocytes and microsomes. Drug Metab Dispos 33:1304-1311.

Shibata Y, Takahashi H, Chiba M, and Ishii Y (2002) Prediction of hepatic clearance and availability by cryopreserved human hepatocytes: an application of serum incubation method. Drug Metab Dispos 30:892-896.

Si-Tayeb K, Noto FK, Nagaoka M, Li J, Battle MA, Duris C, North PE, Dalton S, and Duncan SA (2010) Highly efficient generation of human hepatocyte-like cells from induced pluripotent stem cells. Hepatology 51:297-305.

Smith CM, Nolan CK, Edwards MA, Hatfield JB, Stewart TW, Ferguson SS, Lecluyse EL, and Sahi J (2012) A comprehensive evaluation of metabolic activity and intrinsic clearance in suspensions and monolayer cultures of cryopreserved primary human hepatocytes. J Pharm Sci 101:3989-4002.

Sohlenius-Sternbeck AK, Jones C, Ferguson D, Middleton BJ, Projean D, Floby E, Bylund J, and Afzelius L (2012) Practical use of the regression offset approach for the prediction of in vivo intrinsic clearance from hepatocytes. Xenobiotica 42:841-853.

Tostões RM, Leite SB, Miranda JP, Sousa M, Wang DIC, Carrondo MJT, and Alves PM (2011) Perfusion of 3D encapsulated hepatocytes-a synergistic effect enhancing long-term functionality in bioreactors. Biotechnol Bioeng 108:41-49.

Turpeinen M, Tolonen A, Chesne C, Guillouzo A, Uusitalo J, and Pelkonen O (2009) Functional expression, inhibition and induction of CYP enzymes in HepaRG cells. Toxicol In Vitro 23:748-753.

Vivares A, Salle-Lefort S, Arabeyre-Fabre C, Ngo R, Penarier G, Bremond M, Moliner P, Gallas JF, Fabre G, and Klieber S (2015) Morphological behaviour and metabolic capacity of cryopreserved human primary hepatocytes cultivated in a perfused multiwell device. Xenobiotica 45:29-44.

Williams JA, Hyland R, Jones BC, Smith DA, Hurst S, Goosen TC, Peterkin V, Koup JR, and Ball SE (2004) Drug-drug interactions for UDP-glucuronosyltransferase substrates: a pharmacokinetic explanation for typically observed low exposure (AUC/AUC) ratios. Drug Metab Dispos 32:1201-1208.

Address correspondence to: Dr. Patrick Barton, Evotec, 114 Innovation Drive, Milton Park, Abingdon, Oxford OX14 4RZ, UK. E-mail: patrick.barton@evotec.com 